\title{
Relacions hipertextuals en Judit (1929), de Josep Maria de Sagarra
}

\section{Hypertextual relationships in Judit (1929), by Josep Maria de Sagarra}

\author{
Ramon X. Rosselló \\ Universitat de València \\ Ramon.Rosello@uv.es
}

\begin{abstract}
This article is a monograph focusing on an analysis of the play Judit by Josep M. de Sagarra. The author's only tragedy, and unique among his works, was first performed in Barcelona in 1929. It is a little-studied work, doubtless due to its lack of success with theatre audiences, although Sagarra himself had a high opinion of it. To carry out our analysis, we will make use of the analytic tools introduced by Gérard Genette in his Palimpsestes (1982) around hypertextuality and, more specifically, we will consider this work as a transformation of the biblical story, paying special attention to the new material Segarra brought to this text.
\end{abstract}

Keywords: Catalan theatre, tragedy, Judith, Josep M. de Sagarra, hypertextuality, Bible

\section{INTRODUCCIÓ}

L'objecte d'estudi d'aquest article és l'obra Judit (1929), de Josep Maria de Sagarra (Barcelona, 1894-1961), sens dubte una peça singular en la trajectòria del nostre autor $^{1}$. Efectivament, podem considerar-la una raresa dins la producció de Sagarra, tant des del punt de vista del gènere com del material ficcional. També en el context

\footnotetext{
${ }^{1}$ Aquest text s'estrenà el 16 d'abril de 1929 al Teatre Novetats, a Barcelona (Sagarra, 2009, p. 507).
} 
teatral català del moment, l'escriptura d'una tragèdia basada en un motiu bíblic és un fet inusual, un context, recordem, caracteritzat sobretot pels poemes dramàtics i les comèdies burgeses (Casacuberta, Foguet, Gallén \& Gibert, 2011, p. 147-148). L'origen d'aquesta peça, d'acord amb el que explicava Sagarra (1979, p. XXII), es pot vincular a canvis en la direcció del Teatre Novetats:

Amb la direcció de Capdevila entrava al Novetats un altre aire, més d'acord amb les ambicions del dia. La primera obra que ell em posà, i dirigí amb tot l'afecte, fou, però, el fracàs més gran del meu teatre. [...] Jo confesso que presentar a un públic burgès una interpretació del cas de Judit, com vaig presentar jo, demanava una certa audàcia. La fredor més gran i algun xiulet, coronaren l'esforç meu i l'esforç del director. I que consti, jo crec que Judit és una de les meves obres que, perquè no estan escrites amb cap concessió a la galeria, potser conserven a través dels anys una mica d'aquella dignitat que vaig intentar donar-li.

Comprovem que la recepció de Judit per part del públic tingué repercussió en l'escriptura de Sagarra, ja que, tal com expliquen Gallén i Gustà (1987, p. 483), aquest "tragué una definitiva lliçó: el públic només responia de forma positiva al seu teatre en vers $[\ldots]$ i centrat, temàticament, en el que ell en deia el sentit de la terra".

Amb Judit ens trobem davant un text poc difós i analitzat, amb comentaris molt breus a la bibliografia teatral. Carbonell (1964, p. 1390), a l'epíleg a l'obra dramàtica de Sagarra, situa aquesta peça en una segona etapa de l'autor, "la plenitud neoromàntica (1927-1936)" i la valora "com una de les obres més estimables". Curet (1967, p. 572) assenyala que era una "versió ben atrevida de la tragèdia bíblica". Posteriorment, Fàbregas (1978, p. 227) considera que amb Judit Sagarra "no aconsegueix d'ultrapassar les zones dels convencionalismes". Palau i Fabre (2004), dins el seu repàs a l'escriptura de tragèdies a Catalunya, n'inclou un comentari, tot relacionant-la amb el context en què fou estrenada, el qual recollirem posteriorment. No serà fins a l'edició de l'Obra Completa de Sagarra, a càrrec de Tres i Quatre, quan Gibert (2006) dedique atenció a la peça, tot recordant altres versions de Judit, les quals mostren l'interés que el personatge va despertar en el teatre europeu del segle XIX i principis del XX. Es tracta de les peces de Christian Friedrich Hebbel (1841), la de Georg Kaiser (1911), titulada Die jüdische Witwe, la de Henry Bernstein (1922), la d'Azorín (1926) i la posterior de Jean Giraudoux, estrenada el 1931. No oblidem, però, que aquest referent compta, igualment, amb una tradició literària, i no només teatral, així com també amb una presència destacada en altres camps artístics².

Amb l'objectiu d'aprofundir en les reescriptures contemporànies fetes a partir de mites, volem analitzar Judit, específicament, des de la perspectiva de les relacions

${ }^{2}$ En aquest sentit, es pot veure Dijkstra (1994) i Bornay (2018). Tots dos vinculen les representacions plàstiques de Judit de la segona meitat del segle XIX i principis del XX amb l'arquetip de la dona fatal. Les limitacions pròpies d'aquest format ens porten a deixar aquesta qüestió per a un altre treball. 
hipertextuals, d'acord amb la teorització de Gérard Genette a Palimpsestes (1982). Segons expliquen Gregori i Rosselló (2018, p. 5-6), "el marc teòric i conceptual de la hipertextualitat s'ha revelat idoni per a l'estudi de les relacions entre mites i literatura", ja que permet "traure a la llum unes relacions [...] que han servit per a mostrar la diversitat de formes i d'estratègies amb què els autors plasmen el diàleg entre la tradició textual i simbòlica heretada i la contemporaneïtat". En el cas de Judit, segons els plantejaments de Genette, ens trobem en el terreny de les transformacions, diferent de les imitacions, on el referent seria un gènere, la producció d'una època o escola, o la producció sencera d'un autor ${ }^{3}$. Així, ens centrarem en una anàlisi comparativa entre "Llibre de Judit", l'hipotext bíblic, i la peça Judit, l'hipertext. Tot seguint el model proposat per Genette, n'abordarem l'anàlisi tenint en compte la distinció entre la transformació o transposició formal i la temàtica. Ara bé, arran de la lectura de la crítica del moment, també establirem connexions amb altres textos, les quals ens semblen interessants d'incorporar en aquest acostament a la reescriptura de Sagarra.

\section{LA TRANSPOSICIÓ FORMAL}

En aquest cas resulta força interessant la dimensió formal, ja que ens trobem, en termes de Genette (1982, p. 323), davant una "transmodalització intermodal”, és a dir, la dramatització d'un text narratiu. Aquesta transformació té repercussions, d'entrada, en la caracterització genericoestructural de l'obra: "misteri en tres actes" en diu Sagarra (p. 507)4. L'ús del terme "misteri”, que podríem qualificar de singular, no és obstacle perquè tots els que s'hi han referit hagen adscrit el text al gènere de la tragèdia. En aquest sentit, Palau i Fabre (2004, p. 22) comentava que "encara que ell no l'anomeni tragèdia, la seva Judit ha de ser considerada una tragèdia, però el pes del Noucentisme hi és tan aclaparant, que el seu autor ni s'atreveix a designar-la així. El sol mot hauria espaordit $i$ allunyat els espectadors. [...] El terme Misteri pot ser entès a la manera grega, o pot ser entès d'una manera més immediata, religiosa".

La dramatització comporta, entre altres aspectes, transposar un material ficcional, presentat en 16 capítols, a una estructura dramàtica en actes, ajustada a determinades convencions. Això suposa la tria d'uns espais d'acció, que en aquest cas es concreta, com detallarem després, en un de diferent per a cada acte i en un desenvolupament temporal marcat per dues el·lipsis. Podem destacar que, a diferència del que veiem

\footnotetext{
${ }^{3}$ També es podria abordar l'anàlisi de Judit des de la perspectiva de la imitació de models teatrals, concretament models de tragèdia. Deixem aquest assumpte per a treballs posteriors, així com també l'anàlisi de l'obra respecte a altres reescriptures com les esmentades. Es pot veure una aproximació breu a altres Judits a Laffont i Bompiani (1984, p. 537-538).

${ }^{4}$ En les remissions de les citacions de Judit només indicarem la pàgina de l'edició emprada en aquest article, corresponent a Sagarra (2009).
} 
en altres peces seues, no se'ns presenta una divisió explícita en escenes, tot i que sí que podem observar-hi una divisió implícita a partir del criteri d'entrada i eixida de personatges, en un nombre reduït, atés que Sagarra, majoritàriament, construeix escenes llargues amb escàs moviment de personatges. A més a més, l'autor opta pel vers decasíl·lab blanc i per un conjunt d'imatges poètiques a l'hora d'articular els parlaments, amb la qual cosa s'allunya encara més, des d'un punt de vista estilístic, del text bíblic.

Entre els elements de transposició formal, també podem situar Judit en el terreny de la reducció, ja que la peça no abraça tot el material diegètic de l'hipotext. Així, l'acció de Judit prescindeix dels 7 primers capítols. Aquesta, però, s'acompanya de transformacions temàtiques que s'interrelacionen amb la reducció, les quals revisarem en l'apartat següent. Sense oblidar la incorporació de personatges que no tenen relació amb el relat bíblic. Ens trobem, per tant, amb una primera conclusió: la reescriptura va molt més enllà de ser una simple dramatització de l'hipotext.

\section{LA TRANSPOSICIÓ TEMÀTICA}

Sobre els aspectes de contingut, podem tornar a la consideració de Sagarra (1979, p. XXII), quan deia que presentar una interpretació de Judit com la seua demanava una certa audàcia. Tot seguit veurem en què consisteix aquesta interpretació i quina podria ser-ne l'audàcia, per a la qual cosa revisarem el que Genette denomina transposicions diegètica i pragmàtica, les quals tenen la seua incidència, finalment, en la transposició semàntica, que abordarem a les conclusions.

\subsection{LA TRANSPOSICIÓ DIEGÈTICA}

La transposició diegètica ens remet al marc històric i geogràfic, és a dir, a l'època $\mathrm{i}$ al macroespai on se situa la ficció, en què també podem incloure el medi social o possibles transformacions al voltant de l'edat dels personatges, el sexe o la seua nacionalitat. Respecte a aquest àmbit, el que observem en Judit és el manteniment del marc espaciotemporal, la qual cosa ens situa en el terreny d'una transformació, en termes de Genette, "homodiegètica". Així, l'acció transcorre igualment a Betúlia en la mateixa època que al relat bíblic. Si bé no trobem cap referència explícita a l'època, en un text que presenta acotacions mínimes, sí que comptem al diàleg amb referències a l'espai, com veiem a l'inici de la primera escena, on es dona informació sobre el context ficcional. Així, en aquesta escena se'ns parla d'una situació de guerra i s'hi esmenta, per primera vegada, el macroespai Betúlia. 


\subsection{LA TRANSPOSICIÓ PRAGMÀTICA}

La transformació pragmàtica es relaciona amb modificació del curs de l'acció, la qual cosa ens porta a qüestions com la motivació de les accions o a canvis en els episodis que conformen la història. En aquest cas, Genette (1982, p. 372) introdueix la consideració de la "transmotivació" de les accions, un camp en què l'obra de Sagarra inscriu gran part dels canvis que la doten de singularitat. Per tal d'analitzar les transformacions pragmàtiques farem una anàlisi de cada un dels actes.

\subsubsection{LA CONSTRUCCIÓ DE L’ACTE PRIMER}

Aquest acte se situa a casa de Judit i s'estructura a partir de 6 escenes, en què intervindran, a banda de Judit i la serventa Sara ${ }^{5}$, tot un seguit de personatges aliens a l'hipotext: Jehú, Gad, Jonàs, Baltasar, Acab, Absolon i El Sant. L'acció, des del punt de vista del desenvolupament del text bíblic, es relaciona amb el capítol 8, en el qual és presentada Judit. El mateix es podria dir que fa Sagarra a les primeres escenes, tot i que la caracterització del personatge és ben diferent. Per dur a terme aquesta presentació comptem amb 5 escenes que no tenen relació amb el relat bíblic. Així, a l'escena 1 trobem els vells mendicants Jehú i Gad, a la 2 Jonàs, un altre vell que sembla viure amb Judit i Sara, i ja a les escenes 4 i 5, Baltasar, amant de Judit, i Acad, pare de Baltasar. En aquesta caracterització destacaríem allò que Judit provoca en els diferents homes que l'envolten o l'opinió que d'aquesta tenen, tot tenint en compte dos elements essencials: la seua bellesa i el fet d'exercir la prostitució. Sobre aquest segon tret, que dota la versió de Sagarra d'un caràcter singular, tornarem després.

Es podria dir que l'acció, amb l'escena 6, tot i les transformacions, connecta amb l'hipotext a partir del versicle 11 del capítol 8. Ara bé, Sagarra no fa venir els ancians de Betúlia a casa de Judit a petició d'aquesta sinó que aquests, encara que ni amb els mateixos noms ni comportaments, s'hi presenten per tal que Judit actue per salvar la ciutat, a partir d'una petició prèvia d'Holofernes: "El foc no lleparà les vostres tendes / si aquesta nit puc abraçar una dona / que es diu Judit i és filla de Betúlia” (p. 530). Així, malgrat les diferències que hi veiem, considerem que Absolon i El Sant, "dos homes principals" (p. 527), poden ser vistos com el correlat dels bíblics Ozies, Cabrís i Carmes. Hi trobem, per tant, una transmotivació pel que fa a les raons de per què Judit acabarà decapitant Holofernes, acte central d'aquest relat. No serà fruit d'una iniciativa pròpia, com s'explica al capítol 8 , sinó que Judit es veurà forçada a fer-ho, dins un pla que Absolon i El Sant li exposen amb l'objectiu de derrotar el general assiri.

${ }^{5} \mathrm{Al}$ relat bíblic trobem una serventa sense nom, que, així com Judit, fa acte de presència al capítol 8 i participa, encara que de manera puntual, a l'acció. 
Per aconseguir-ho plantegen que li talle el cap amb la seua espasa, que se l'enduga i que a dalt les muralles es mostre aquest cap. Judit, inicialment, refusa el pla, però ells li expliquen que d'aquesta manera els assiris no tindran l'empenta que els dona el cabdill i seran vençuts. Veiem que el contingut d'aquest pla sí que coincideix amb el relat bíblic que, seguint l'ordre lineal de l'acció, trobem a part dels capítols 13, 14 i 15. La resposta de Judit serà seguir negant-s'hi: “jo no em vull vendre per les coses vostres / ni per la calma de les vostres filles" (p. 535). En aquest punt sorgeix un dels temes més interessants del text, la pàtria, sobre la qual Judit diu: "De la pàtria m'has dit? ¿I sou vosaltres, / vostra avarícia i vostres conveniències, / i la por que us rosega les entranyes, / la vostra llar amb tuf d'hipocresia, / i el vostre jaç tranquil, això és la pàtria?" (p. 536).

Finalment, aquesta accepta el que proposen, però deixant clar que "si faig això que faig no és per vosaltres" (p. 537). I l'acte acaba amb un llarg parlament de Judit, en què n'exposa les raons. Judit hi fa una contraposició entre un vosaltres, representat per Absolon i El Sant, i uns altres, pels quals actuarà: "jo sé que hi ha carn vella i carn cansada / que encara té la feina de les bèsties, / treballant i suant nit i dia, / i és per aquesta carn martiritzada [...]. / Per aquests, s'entén bé, no per vosaltres” (p. 538-539).

\subsubsection{LA CONSTRUCCIÓ DE L’ACTE SEGON}

Tot i que amb canvis importants respecte a aspectes concrets, l'inici de l'acte es relaciona amb el capítol 10 de l'hipotext, sense que hi trobem cap rastre del 9. L'acció s'ubica a la tenda d'Holofernes, espai que es correspon amb el del final del capítol 10, tot desapareixent del text de Sagarra l'acció prèvia a l'arribada de Judit a la tenda (els 19 primers versicles). Concretament, ens situem a l'avantcambra, tal com diu el text bíblic, ja que després Sagarra ens parlarà de la cambra d'Holofernes, un espai contigu. En aquest acte ens trobem amb una estructura de 6 escenes i amb la intervenció, a més de Judit i Sara, de tres personatges que no havien fet acte de presència: Holofernes, Barac i, de manera puntual, Esclau. Sobre Barac, aquest es podria relacionar amb Bagoes, presentat a l'hipotext com "l'eunuc que duia tots els seus assumptes" (p. 1426) ${ }^{6}$.

Les dues escenes inicials, que no tenen un correlat a l'hipotext, ens porten al moment previ a l'arribada de Judit. En aquestes s'introdueix, davant l'estranyesa de Barac, la motivació de per què Holofernes ha sol-licitat la presència d'aquesta. Així, Sagarra amplia i detalla la transmotivació ja exposada, la qual cosa incideix en la caracterització del general. Les raons del seu comportament són plantejades des de l'avorriment per fer sempre el paper de "monstre", la rutina de la guerra i les ganes

${ }^{6}$ En les remissions de les citacions bíbliques només indicarem la pàgina de l'edició emprada en aquest article, corresponent a la Bíblia Valenciana Interconfessional (1996). 
d'estar amb una dona (p. 546). En aquesta situació, Barac l'adverteix reiteradament de les dones, a la qual cosa respondrà amb supèrbia que "la carn de les femelles / no llimarà les ungles d'Holofernes" (p. 548), una supèrbia que adquireix, si més no, una dimensió irònica.

L'escena 3 connecta amb el versicle 20 del capítol 10: "La guàrdia personal i els oficials d'Holofernes van eixir i feren entrar Judit a la tenda" (p. 1424). A diferència del relat bíblic, però, l'acció s'articula només al voltant de la interacció entre Judit, Sara i Holofernes, tot eliminant-ne el capítol 12. Cal tenir en compte que, des del punt de vista temporal, l'acció dels actes 1 i 2 es localitza en un mateix dia, mentre que a l'hipotext Judit romandrà al campament quatre dies (capítols 10, 11, 12 i part del 13). Es pot considerar que d'aquesta manera Sagarra ens situa directament en el moment en què al relat bíblic Judit i Holofernes es queden sols i, a continuació, ella li talla el cap (capítol 13), tot i que seguint l'estructura d'un llarg diàleg entre ambdós, com el que té lloc al capítol 11. En el transcurs del diàleg entre Judit i Holofernes a les escenes 3 i 4, ben allunyat d'aquell present a l'hipotext, veurem una interacció entre dos personatges en evolució: de la sorpresa inicial per part de Judit que Holofernes no la mate a un cert "desvetlament" interior i a una connexió de dos personatges atrapats en allò que semblen ser per als altres. En el cas d'Holofernes la dualitat es formula amb la dicotomia monstre/home (p. 552) i amb un significatiu "Que fóra dolç, deixar de ser Holofernes!" (p. 562), punt culminant d'aquest desvetlament, al qual Judit respon (p. 562): “¿Deixar de ser Judit no fóra encara / més dolç que això que dius? [...]; / deixar de ser Judit, però per sempre, / i ser una dona, un tros de carn de dona / lligat a la crinera d'Holofernes!".

Ara bé, aquest moment d'eventual connexió, que en el cas de Judit es concreta a la fi en un enamorament, acaba amb una reacció de rebuig del general. Així, davant una possible debilitat del general, aquest afirma que "Holofernes ja torna a ser Holofernes..." (p. 562), tot i que el personatge deixa la porta oberta a "fer-la seua". Cal tenir en compte, però, que aquest no passarà la nit amb Judit $i$ alhora li deixarà clar que no se sent obligat a complir el tracte: "Demà rebentarem totes les portes / i el foc menjarà el rastre de Betúlia" (p. 563). En aquest punt, si bé podem dir que Sagarra ens situa al capítol 13, en el moment en què Judit i Holofernes es queden sols, és interessant veure que, a diferència del relat bíblic, on Holofernes se'n va al llit ebri després d'un banquet, aquest altre Holofernes fa notar que "la gerra del licor, guaita, és ben plena; estic serè” (p. 562).

A més de simplificacions o reduccions respecte a l'hipotext, veiem que Sagarra introdueix importants novetats, com ara l'enamorament de Judit, en un gir sobtat de l'acció. L'escena 5 , formada per un breu monòleg d'aquesta, serveix per expressar la seua estima cap al general, tot $\mathrm{i}$ que finalment es decidirà a dur a terme el que li ha estat demanat, impulsada pel que aquest ha dit que farà contra el poble de Betúlia, amb la qual cosa també Judit tornarà a ser Judit: "Judit no et vol matar, són aquests 
braços / afadigats i mossegats d'infàmia / que ara porten a dintre de les venes / tota la sang més viva del meu poble!" (p. 567) ${ }^{7}$. L'acte acaba, però, just abans que aquesta mate Holofernes, ja que amb Sagarra no arribarem al moment icònic de la decapitació.

\subsubsection{LA CONSTRUCCIÓ DE L'ACTE TERCER}

L'acte ens trasllada a allò que passà després de la derrota dels assiris, tot tenint en compte que entre la fi de l'acte 2 i l'inici del 3 Sagarra planteja una el-lipsi de tres dies (p. 578). Si fem un paral·lelisme amb el text bíblic, ens traslladaríem al capítol 15. Ara bé, al llarg de l'acte, mitjançant retrospeccions indirectes, es narra allò que passà després de la fi de l'acte 2, com ara la descripció de la mort d'Holofernes. En realitat, amb aquest acte s'altera totalment l'acció de l'hipotext. Així, l'acte, construït amb 5 escenes, és localitzat a la denominada "espluga de la mort", un espai aliè al referent bíblic, i compta amb la participació, inicialment, de Jonàs, Sara i Judit, i, posteriorment, d'Absolon, El Sant i uns soldats. Com déiem, les dues primeres escenes serveixen, per una banda, per completar la informació del que ha transcorregut entre l'acte 2 i el present de l'acció. A més, comprovarem que, enfront del que veiem al relat bíblic a partir del versicle 8 del capítol 15, Judit ha hagut de fugir de casa i, a més, ha estat abandonada per Baltasar, el seu amant fervent.

D'aquesta manera, el final feliç de la Judit bíblica, que es completa al capítol 16, es transforma en un desenllaç tràgic, tot atorgant un final totalment oposat a la vida de l'heroïna bíblica ${ }^{8}$. Així, diríem que del versicle 8 del capítol 15 ("El gran sacerdot Joaquim i el consell d'ancians israelites, que vivien a Jerusalem, van venir per contemplar els grans beneficis que el Senyor havia concedit a Israel. Volien veure també Judit i saludar-la" [p. 1429]), passem a una situació en què Judit ha hagut de refugiar-se davant la reacció del poble. Això sí, en aquesta situació, aquesta també rebrà visita, la d'aquells que l'havien anat a veure per demanar-li que matés Holofernes. En aquest acte Sagarra introdueix una transformació radical respecte al relat bíblic, l’origen de la qual es relaciona amb la caracterització dels "homes" de Betúlia i la seua resposta davant la victòria a partir de la intervenció de Judit, una altra transmotivació destacada, que, sens dubte, queda marcada pel fet que Judit és dona i prostituta.

Serà mitjançant la visita del jutge Absolon (escena 3) com se'ns informe de per què Judit es troba en aquesta situació: "Ara els sants i els valents i tots els homes / ne-

${ }^{7}$ Genette (1982, p. 379-380) comenta respecte a les versions modernes de Judit que per tallar el cap una dona a un home poden haver-hi dos motius: que l'haja menyspreada o posseïda. En aquest cas, veiem una Judit "rebutjada" però no sembla que actue per despit sinó per salvar el poble, amb la qual cosa la motivació última sí que es relaciona amb l’hipotext. Ara bé, la diferència, ben significativa, rau en el concepte de poble o pàtria.

${ }^{8}$ Recordem que al versicle 23 del capítol 16 es diu que "Judit va arribar a una edat molt avançada. Anà envellint a la casa del seu marit fins a l'edat de cent cinc anys" (p. 1430). 
guen que siguis tu qui va salvar-los" (p. 576). Així, el motor d'aquest desenllaç tràgic és, segons Absalon, que "hi ha veritats que fiblen" (p. 577) i que s'ha difós una altra versió dels fets: "Conten, Judit, que tu vas dir a Holofernes / les intencions dels homes de Betúlia [...], / que fou un d'ells el que tallà la testa [...]. / I, a més a més dels crims que de tu es conten, / hi ha el crim aquest de traïció a la pàtria" (p. 578-579). Absalon, així mateix, li explica que, si ella va actuar pensant en el poble humil, ara és aquest el que diu "coses més horribles" (p. 579) i demana la seua mort, un comportament que s'explica de la manera següent: "Primer són els profetes que prediquen, / i després són els pobres que els escolten, / i el ramat ja és encès..." (p. 580). En aquest punt també destaca com Absolon respon a Judit davant les peticions d'aquesta perquè intervinga a favor seu: "quantes vegades / a contracor jo signo les sentències, / per no ferir la voluntat del poble!" (p. 580). En aquesta escena resulta ben rellevant el que diu Absolon sobre quina interpretació se'n farà en el futur (p. 583): "Potser amb el temps, Judit, la teva història / serà untada de mel, potser altres llengües / desfaran tot el crim i la injustícia, / i et vestiran amb un vestit de santa".

Finalment, aquest li explica que demanen que siga cremada. Veurem que Judit, a l'escena 4, intenta escapar-se'n i salvar-se de la foguera. L'escena final queda marcada per l'arribada del Sant i quatre soldats que tenen la funció d'endur-se-la. En aquesta Sagarra ens mostra com El Sant menteix i fa, davant els soldats, com si no la conegués, la qual cosa intensifica el retrat negatiu de les autoritats. L'obra acaba just en el moment en què estan per emportar-se Judit i aquesta "cau morta" (p. 593).

\section{MÉS ENLLÀ DE L'HIPOTEXT BÍBLIC}

Sobre el fet que Sagarra convertís Judit en una prostituta, Gibert (2006, p. XLII) plantejava que no podem desvincular aquesta caracterització "del gust per la marginalitat característic de l'expressionisme dramàtic, del teatre nord-americà d'Eugene O'Neill, i fins i tot del teatre de bulevard més atent als fenòmens socials del període d'entreguerres"'. Però, a més d'aquestes motivacions, resulta força interessant la relació que alguns crítics van establir entre Judit $i$ altres autors i textos, especialment amb dues obres concretes.

La primera d'aquestes incideix directament en el personatge de la prostituta: Bola de greix (Boule de Suif), de Guy de Maupassant (2010), publicat originalment l'any 1880. Així ho veiem a la crítica de La Vanguardia: "El poema «Judit», en la vuelta que se da al tema, con relación al libro sagrado, nos sugirió, sin saber por qué, que el

\footnotetext{
${ }^{9}$ Sobre la prostitució, Bornay (2018, p. 60), tot situant-se en el context de la segona meitat del segle XIX, recorda que el creixement i l'extensió de la prostitució "proporciona otro de los parámetros que, una vez más en la historia de la misoginia, coadyuvaron a ver a la mujer como elemento corruptor y transgresor, no sólo de la moral burguesa imperante, sino también de la ley divina que ordena no caer en los pecados de la carne". Aquesta és, sens dubte, la mirada pròpia de personatges com Acab, Absolon o El Sant.
} 
autor pudo idearlo habiendo leído primero el texto bíblico y luego "Boule de suif»" (Rodríguez Codolá, 1929) ${ }^{10}$. Una relació, ben plausible al nostre parer, que incidiria no només en la caracterització de Judit com a prostituta, sinó en el paper que aquesta juga en el desenvolupament de l'acció i en la relació que els altres personatges mantenen amb aquesta. Així, a Bola de greix l'acció se situa a França durant la guerra francoprussiana de 1870, en un viatge amb diligència que fan deu personatges, entre els quals destaca com a protagonista la prostituta Élisabeth Rousset, de malnom "Bola de greix". Al llarg del camí, i davant el fet que el viatge fins a una posada s'allarga de manera inesperada, la prostituta compartirà una cistella de menjar amb la resta de personatges, majoritàriament pertanyents a classes benestants; i això, malgrat que aquests no s'havien comportat especialment bé amb ella durant el trajecte. Arribats a la posada, un oficial prussià decideix no deixar-los continuar el viatge fins que Bola de greix passe una nit amb ell. Aquesta, inicialment, no n'acceptarà la proposta. Progressivament els altres personatges la impulsaran a fer-ho, cosa que acabarà passant. En reprendre el viatge, els altres trauran el menjar agafat per al nou trajecte. Però Bola de greix, que no ha pogut preparar res, veurà que cap dels seus acompanyants li n'oferirà.

Resulten evidents els lligams amb la transmotivació sagarriana dels dos primers actes. És cert, però, que el desenllaç de les obres és diferent, la qual cosa ens porta a un segon text, també citat per la crítica, Santa Joana (1923), de G. B. Shaw, com veiem en textos publicats a La Veu de Catalunya (P. B., 1929), Gaceta deportiva (J. M. P., 1929) o La Publicitat (Guansé, 1929). Des de Mirador, a més de vincular la peça amb Santa Joana, es deia que "volem defensar l'originalitat de l'obra. S'ha parlat de Santa Joana, de Bernard Shaw. Ben mirat, el personatge de l'obra d'En Sagarra és una Judit que mor com Joana d'Arc. Però el paral·lelisme, la fusió de les dues històries -i això és la clau de l'obra- és molt original" (Brunet, 1929). Recordem que el text de Shaw tingué una primera edició en català publicada a Barcelona el 1927, amb traducció de Carles Capdevila i C. Fernàndez Burgas ${ }^{11}$, el mateix Capdevila que dirigí Judit el 1929. En aquest cas, si bé ens trobem amb un text teatral, formalment és molt diferent, tant per l'estructura com per estar escrit en prosa. Així, la relació es concretaria en el paper que juga Joana d'Arc en la victòria dels francesos i, sobretot, en la manera com aquesta mor, a la foguera, en una situació en què aquells a qui va ajudar, especialment el Delfí de França, no s'esforcen per evitar el seu desenllaç tràgic.

\section{CONCLUSIONS}

Podem concloure que, en aquesta transformació -en termes de Genette- seriosa, destaquen les transposicions pragmàtiques, atés que les coordenades espaciotempo-

\footnotetext{
${ }^{10}$ També es relaciona Judit amb el relat de Maupassant a D'ací i d'allà (Nicol, 1929).

${ }^{11}$ Vegeu l'edició moderna de l'obra (Shaw, 1986).
} 
rals no són modificades. Diríem que Sagarra, amb aquestes, ens descobreix una altra versió, una altra "interpretació" en deia ell, com si la versió que ens ofereix fos la vertadera i aquella que conté la Bíblia fos resultat del que Absolon veia possible que passés en un futur, en què irònicament la "traïdora" passaria a ser "herö̈na", així com Joana d'Arc passà d'heretge a santa. En aquest sentit, la proposta de Sagarra connectaria amb allò que Genette (1982, p. 380) comenta sobre la versió de Giraudoux, en el sentit que l'hipertext modern s'encarrega de descobrir el que realment va ocórrer. Evidentment, aquest descobrir va vinculat a allò que l'autor projecta sobre l'hipotext, ja que, en el fons, i ací trobem el punt clau de la transformació, els homes no podien haver assumit la "veritat". Només amb una transformació de la "veritat", on Judit ja no és una prostituta víctima dels poderosos, sinó una vídua exemplar, aquesta acaba sent una personificació de "l'âme de la résistance du peuple juif fermement appuyé sur sa foi en Dieu" (Labre, 2002, p. 180).

Amb aquesta Judit, Sagarra suma a allò que anomenem pàtria o poble (jueus vs. assiris) un altre element de retrat social, a partir de la distinció entre les classes dirigents i el poble pobre i sotmés, pel qual acabarà actuant Judit. Així, l'oposició principal, representada per la pàtria en l'hipotext, deriva en la simbolitzada per El Sant i Judit en l'hipertext. A més, en la proposta de Sagarra veiem un altre element social, com és la diferència de sexe (o gènere), dins una obra en què Judit està envoltada de personatges masculins que volen utilitzar-la, inclòs Holofernes, per satisfer els seus desitjos. La diferència entre homes i dones és un element que trobem des l'acte primer, quan assistim a la defensa que Judit fa de les dones: "Us penseu que només el braç del mascle / és el que pot desencongir les fones / i cargolar les negres cabelleres. / [... ¿No saps que dins del ventre de les dones / és allí on dorm la fúria dels miracles?’ (p. 521). Sagarra projecta així sobre el relat bíblic el retrat d'un medi i d'uns comportaments que, alhora, podem projectar sobre el present de l'escriptura, amb relació a qüestions com el gènere, les diferències socials i el concepte de "pàtria". De tot plegat es desprén un escepticisme profund respecte al comportament d'aquestes classes dirigents, esdevingudes diana de les crítiques. Podem concloure, per tant, tot seguint Herrero (2006, p. 74), que aquesta transformació manifesta una tasca de "reorientació" respecte a l'hipotext bíblic que, si bé es relaciona amb la sensibilitat artística de l'època -"més d'acord amb les ambicions del dia", en deia Sagarra (1979, p. XXII)-, respon també a una visió personal sobre el món.

Al capdavall, i tornem a l'inici, el públic no va respondre positivament a aquesta reescriptura, la qual podria haver reorientat la trajectòria de Sagarra. Com s'afirma en algunes crítiques i estudis, ens trobem davant una peça marcada per l'atreviment i un públic desacostumat a aquest tipus d'obres. És difícil esbrinar fins a quin punt hi pesaren, per una banda, les característiques de la versió de Sagarra i, per una altra, les expectatives, els gustos i la ideologia d'un públic avesat a altres models sagarrians $i$, en general, a altres models teatrals. El ben cert és que amb Judit no es va poder encetar un nou rumb en l'obra de Sagarra i, per extensió, en el teatre català de finals dels anys 
vint. Caldrà un nou context perquè acostaments a mites grecs i bíblics des del teatre, com els de Salvador Espriu, assolisquen el reconeixement i la valoració d'aquesta literatura de segon grau.

\section{AGRAÏMENTS}

Aquest treball s'inscriu dins el projecte d'investigació del Ministerio de Ciencia e Innovación FFI2017-86542-P titulat La literatura de segundo grado: las relaciones hipertextuales en la literatura catalana desde el "Modernisme" hasta 1939. Més informació sobre l'activitat del grup investigador a: http://www.uv.es/ironialitcat/. 


\section{REFERÈNCIES BIBLIOGRÀFIQUES}

Bíblia Valenciana Interconfessional (1996). València: Saó.

Bornay, E. (2018). Las hijas de Lilith. Madrid: Ediciones Cátedra.

Brunet, M. (1929). Judit, poema en tres actes de Josep Maria de Sagarra. Mirador, 13, 5.

Carbonell, J. (1964). L'obra dramàtica de Josep Maria de Sagarra. Dins J. M. de Sagarra, Obres Completes, IV. Teatre (p. 1345-1406). Barcelona: Selecta.

Casacuberta, M., Foguet, F., Gallén, E. \& Gibert, M. M. (2011). Estudi introductori. Dins M. Casacuberta, F. Foguet, E. Gallén \& M. M. Gibert (eds.). El debat teatral a Catalunya. Antologia de textos de teoria i crítica dramàtiques: del Modernisme a la Guerra Civil (p. 17-148). Barcelona: Institut del Teatre.

Curet, F. (1967). Història del teatre català. Barcelona: Aedos.

Dijkstra, B. (1994). Ídolos de perversidad (trad. de V. Campos González). Madrid: Debate.

Fàbregas, X. (1978). Història del teatre català. Barcelona: Millà.

Gallén, E. \& Gustà, M. (1987). Josep Maria de Sagarra. Dins M. de Riquer, A. Comas \& J. Molas (dirs.), Història de la literatura catalana, 9 (p. 463-496). Barcelona: Ariel.

Genette, G. (1982). Palimpsestes. La littérature au second degré. París: Éditions du Seuil.

Gibert, M. M. (2006). Introducció al teatre de Josep Maria de Sagarra. Dins J. M. de Sagarra, Obra Completa, 15. Teatre 1 (p. VII-LII). València: Tres i Quatre.

Gregori, C. \& Rosselló, R. X. (2018). Pròleg. Dins C. Gregori \& R. X. Rosselló (eds.). L'empremta del mite en la literatura del primer terç del segle XX (p. 5-8). Barcelona: Publicacions de l'Abadia de Montserrat.

Guansé, D. (1929, 18 d'abril). "Judit”, poema en tres actes, de Josep Maria de Sagarra. La Publicitat, p. 6. Herrero, J. (2006). El mito como intertexto: la reescritura de los mitos en las obras literarias. Çedille, 2, 58-76.

J.M.P. (1929, 18 d'abril). "Judit", drama en tres actos, de J. M. de Sagarra. Gaceta deportiva, p. 11.

Labre, C. (2002). Dictionnaire biblique culturel et littéraire. París: Armand Colin.

Laffont, R. \& Bompiani, V. (1984). Dictionnaire des Personnages. París: Robert Laffont.

Maupassant, G. de (2010). Bola de greix (trad. de Ll. Calderer). Berga: Edicions de l'Albí.

Nicol, E. (1929). L'escena. D'ací i d'allà, 137, 177.

P. B. (1929, 18 d'abril). “Judit”, poema en tres actes de Josep M. de Sagarra. La Veu de Catalunya, p. 7.

Palau i Fabre, J. (2004). Problemàtica de la tragèdia a Catalunya. Barcelona: Institut del Teatre.

Rodríguez Codolá, M. (1929, 18 d'abril). "Judit”, poema, en tres actos, de don José María de Sagarra. La Vanguardia, p. 12.

Sagarra, J. M. de (1979). Obres Completes, I. Teatre. Barcelona: Selecta.

Sagarra, J. M. de (2009). Obra Completa, 18. Teatre, 4. València: Tres i Quatre.

Shaw, B. (1986). El deixeble del diable / Santa Joana (trad. de C. Capdevila \& C. Fernàndez Burgas). Barcelona: Edicions 62. 